Jolanta Miturska-Bojanowska

Szczecin, badacz niezależny

tel. +48 692679473

e-mail: jmbnew@wp.pl

ORCID ID: https://orcid.org/0000-0001-5439-2319

\title{
Слова-бленды в газетных заголовках
}

Ключевые слова: газетные заголовки, гаплологические бленды, тмезис

\section{Введение}

Привлечь внимание читателя интересным заголовком - цель каждого журналиста, особенно в настоящее время, когда человек постоянно находится в потоке информации. В связи с этим, по нашему мнению, среди разных задач газетных заголовков, на первый план выдвигается их рекламная функция. Одним из средств ее осуществления в современных печатных СМИ является применение контаминантов (слов-блендов) в строении газетного заголовка.

\section{Типология контаминантов}

Контаминационные процессы (блендинг) происходят на разных уровнях русского языка, чаще всего на лексическом, фразеологическом и синтасическом. В центре нашего внимания оказались лишь словообразовательные контаминанты, т.е. такие лексемы, которые возникают в результате словообразовательных процессов путем скрещения формы и семантики двух-трех полнозначных синтагматически не связанных лексических единиц (ср. [Митурска-Бояновска 2020, 
178-180])1. В структуре слова-бленда могут сохраняться основы, морфемы или, в отличие от сложений и некоторых аббревиатур, только неморфемные отрезки («осколки», квазиморфы) производящих единиц. «Осколочные» контаминанты, возникающие путем амальгамирования, свойствены прежде всего научной терминологии. Некоторые другие блендовые новообразования создаются путем амплификации ${ }^{2}$, т.е. наложения друг на друга омонимичных (изофонных) элементов базовых компонентов, образуя т.н. «замо́к» (междусловное графическое или фонетическое наложение). Созданные таким образом контаминанты являются удобным средством компрессии и кодирования информации в очень компактной материальной форме. В большинстве случаев «газетные» бленды, применяемые журналистами, имеют окказиональный, контекстуальный характер и требуют наличия у читателей фоновых знаний, что осложняет иностранцам понимание содержания и осознание игрового характера газетных заголовков.

Иллюстративный материал, составляющий 64 газетных заголовка, ограничен лишь примерами, почерпнутыми из онлайн-изданий ежедневника «Коммерсантъ» $(\mathrm{b})^{3}$. В выборку вошли заголовки из всех номеров за 2020 г. и из номеров 1-43 за 2021 г.

\section{Гаплологические контаминанты}

С типологической точки зрения среди «газетных» контаминантов превалируют гаплологические $(53 \%)$ и тмезисные (34\%) бленды ${ }^{4}$. В свою очередь, в группе гаплологических контаминатов преобладают

1 Лексический состав русского языка пополняется также за счет фразеологических контаминантов, ср. заголовок «Служба службой, а кресла врозь» [Коммерсантъ, № 11/П от 25 января 2021, (online) https://www.kommersant.ru/doc/4661415 (25.01.2021)], возникший путем скрещения поговорок служба службой, а дружба дружбой и дружба дружбой, а табачок врозь с одновременной заменой компонента табачок лексемой кресла: Служба службой, $\underline{\boldsymbol{a}}$ дружба дружбой. + дружба дружбой, $\underline{\boldsymbol{a}}$ табачок (: кресла) врозь. Во всех приводимых примерах жирным шрифтом обозначаются части мотивирующих компонентов, которые нашли материальное отрожение в контаминанте; общие элементы накладывающиеся друг на друга подчеркиваются.

2 Ср. [Энциклопедический... 2005, 302-303].

3 Лексические контаминанты, применяемые в российских и польских периодических изданиях, стали объектом исследования в работе [Ratajczyk 2015].

4 Больше на тему структрных моделей контаминантов см. [Митурска-Бояновска 2020, 179-180]. 
бленды, в которых амплификации, т.е. наложению друг на друга общих графических/фонетических частей мотивирующих компонентов, сопутствует усечение основ одного или обоих из них, ср.:

- «Книгиня Ольга. Как начитанная министр культуры встретилась с начитанным президентом» [Ъ, № 225 от 08 декабря 2020] ${ }^{5}$ - книгиня

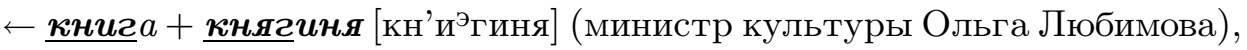

- «С торгцентров сняли ярмаркировку. Перед Новым годом покупатели просто идут по магазинам» [Ъ, № 230 от 15 декабря 2020]

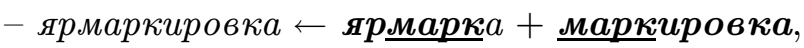

- «Перезанятная история. Граждане активно рефинансируют потребительские кредиты» [Ъ, № 14 от 28 января 2021] ${ }^{7}$ - перезанятная

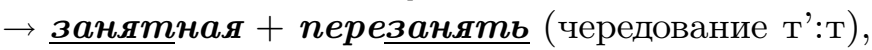

- «Новостройки в льготическом стиле. Кредитование по госпрограмме разменяло триллион рублей» [Ђ, № 3 от 13 января 2021] $]^{8}$ льготический $\leftarrow$ льготный [кредит, ипотека] + экзотический,

- «Пересельская жизнь. Мэрия Москвы рассматривает планы комплексного развития территорий для переселенцев» [Ъ, № 16 от 30 ян-

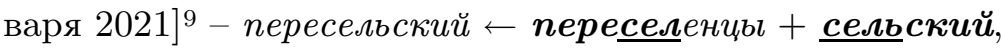

- «Пентагонистические противоречия. Выбранный Джо Байденом кандидат на пост министра обороны США насторожил соратников» [Ђ, № 226 от 09 декабря 2020] $]^{10}$ - пентагонистический $\leftarrow$ Пентагон + антагонистический и пр.

\section{Тмезисные контаминанты}

Интересную, на наш взгляд, группу контаминатнов, представляющую высшую степень языковой игры, репрезентируют тмезисные контаминанты, т.е. бленды, которые образуются путем тмезиса - вклинивания одного слова или его части внутрь другого, нарушая таким образом его первичную структуру ${ }^{11}$. Ряд исследователей, в том числе

\footnotetext{
5 [online] https://www.kommersant.ru/doc/4603694 [08.12.2020].

6 [online] https://www.kommersant.ru/doc/4614939 [15.12.2020].

7 [online] https://www.kommersant.ru/doc/4663345 [28.01.2021].

8 [online] https://www.kommersant.ru/doc/4640963 [13.01.2021].

9 [online] https://www.kommersant.ru/doc/4670668 [30.01.2021].

10 [online] https://www.kommersant.ru/doc/4604718 [09.12.2020].

11 Ср. толкование в Лингвистическом словаре: «Тмезис, англ. tmesis, фp. tmèse, нем. Tmesis, исп. tmesis. Разъединение элементов сложного слова или производно-
} 
А.Ф. Журавлев, Р.Ю. Намитокова и В. Изотов, считают тмезис одним из неузуальных способов словообразования, заключающийся в образовании нового слова путем вставки в исходное другого слова, аббревиатуры, словосочетания, предложения или сегмента слова [Журавлев 1982, 80; Намитокова 1986, 138-139; Изотов 2013, 243]. В связи с этим в лингвистической литературе различаются следующие его типы: сегментный (вставка - морфема или неморфемный сегмент слова) $)^{12}$, аффиксальный (вставка - аффикс) ${ }^{13}$, лексический (вставка самостоятельное слово) ${ }^{14}$ и синтаксический тмезис (вставка - словосочетание или предложение $)^{15}$. Следует также отметить, что расчленяемое слово, как подтверждают наши примеры, не обязательно должно быть композитом или производным словом.

Нами выделяются два вида лексических тмезисных блендов: собственно тмезисные (бленды-«матрешки») и квазитмезисные. Первый из них в структурном плане напоминает игрушки-матрешки, так как внутри одного мотивирующего его компонента «скрывается» другой мотивирующий. При этом в разрываемом и/или вклинивающемся компоненте могут сохраняться либо все его буквы, либо некоторые из них (обычно одна или две) усекаются, ср.:

- «Массовое неповинармение. Оппозиция разворачивает кампанию по отстранению от власти Никола Пашиняна» [Ъ, № 226 от 09 декабря $2020]^{16}$ - неповинармение $\leftarrow$ неповиновение + Армения - неповино ...

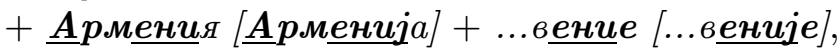

го слова. русск. никого - ни у кого, ничему - ни к чему; англ. whatsoever - What stoicism soever (our wanderer, may affect); howsoever - How long soever (they have been here)» [Ахманова 1966, 475], а также в Энииклопедическом словаре: «олагаем, что уточнить понятие Т. [мезиса] как стилистического приема можно, определив его как такую разновидность вставной конструкции, которая представляет собой вставку (вклинивание) в слово какой-либо языковой единицы (корневой морфемы, слова, аббревиатуры, предложения) [Энииклопедический... 2011, 332].

12 гастбезарбайер (заголовок «Нашествие гастбезарбайтеров», «Нижегородские новости», 18.11.2008) $\leftarrow$ гастарбайтер + без- - гаст.. + без- + ...арбайтер (за: [Шумилова 2010, 133]).

13 «Глава правительства Здраны был мудрым политиком. Он обрадовался, что конфликта не вышло и можно и дальше поневоевать» (П. Калмыков): поневоевать $\leftarrow$ по.. + не $+\ldots$. воевать (за: [Изотов 2017, 117]).

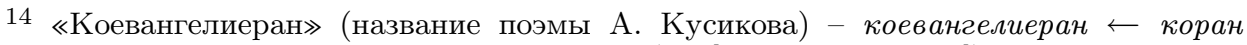
+ евангелие - ко... + евангелие + ...ран (за: [Изотов 2017, 118]).

15 «Мы же - «Санкт-черт возьми!-Петербург?»» (В. Рекшан) - Санкт-черт возьми!-Петербург $\leftarrow$ Санкт-Петербург + + черт возьми! - Санкт-... + черт возьми! + ... -Петербура (за: [Изотов 2017, 118]).

16 [online] https://www.kommersant.ru/doc/4604736 [09.12.2020]. 
- «Израиль замароччился. Первый прямой рейс $\mathrm{El} \mathrm{Al}$ из Тель-Авива в Рабат открыл новую страницу в отношениях двух стран» [Ъ, № 236 от 23 декабря 2020]17 - замароччиться $\leftarrow$ заморочиться + Мароко - за...

- «Оптоповый нефтепродукт. Биржевые цены на бензин приблизились к историческому максимуму» [Ъ, № 10 от 22 января 2021]18

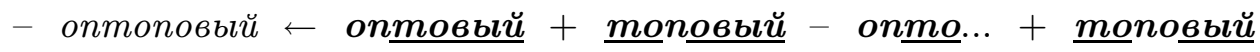
$+\ldots \underline{\boldsymbol{B b l u}}$,

- «КоронОРВИрус» [Ь от 17 апреля 2020]19 - коронОРВИрус $\leftarrow \boldsymbol{\kappa o - ~}$

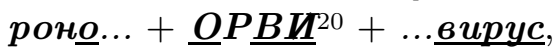

- «Многоотходовая комбинация. «Ростеху» предлагают просить окупаемости своих мусорных ТЭС у регионов» [Ъ, № 20 от 05 февраля $2021]^{21}$ - многоотходовая (комбиначия) $\leftarrow$ многоходовая комбиначия

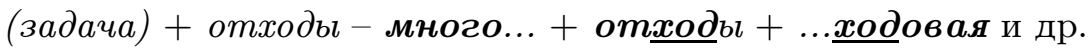

Квазитмезисные бленды - это такие, которые возникают вследствие разрыва структуры узуального слова с помощью второго, причем, в отличие от собственно тмезисных, начальные части обоих исходных компонентов накладываются друг на друга, напр.:

- «Полисейский беспредел. В интернете множатся фальшивые сайты страховых компаний» [Ъ, № 232 от 17 декабря 2020]22 - полисейский

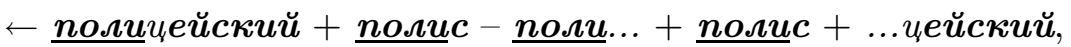

- «Очень обедная ситуация. На рынке поставок еды в школы назревает новый скандал» [Ъ, № 234/П от 21 декабря 2020] $]^{23}$ - обедная

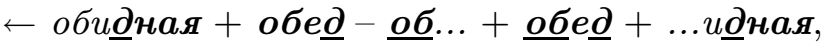

- «Мюнхенская Базария. На конференции по безопасности обсуждают бессилие Запада перед Россией и Китаем» [Ъ, № 28 от 15 февраля

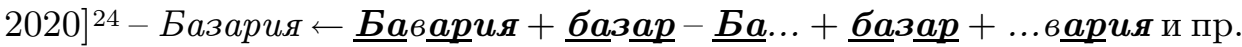

Как показывают приведенные примеры (неповинармение, оптоповый, коронОРВИрус, обедная, Базария) среди тмезисных блендов, в отличие от гаплологических контаминантов, возможны не только одноместные, но и двухместные наложения исходных компонентов.

17 [online] https://www.kommersant.ru/doc/4626723 [23.12.2020].

18 [online] https://www.kommersant.ru/doc/4654926 [22.01.2021].

19 [online] https://www.kommersant.ru/doc/4323805 [10.02.2021].

20 ОРВИ - острые респираторные вирусные инфекции.

21 [online] https://www.kommersant.ru/doc/4674045 [05.02.2021].

22 [online] https://www.kommersant.ru/doc/4616674 [17.12.2020].

23 [online] https://www.kommersant.ru/doc/4624990 [21.12.2020].

24 [online] https://www.kommersant.ru/doc/4258251 [05.10.2020]. 


\section{Агглютинативные и частичные контаминанты}

Кроме гаплологических и тмезисных блендов в газетных заголовках значительно реже применяются агглютинативные и частичные контаминанты, в нашем материале представленные единицами, ср.:

- «Переложение, от которого невозможно отказаться. ЦБ оптимизирует балансы подконтрольных банков» [Ъ, № 219 от 28 ноября 2020] ${ }^{25}$ - переложение $\leftarrow$ [акиии] перейдут + предложение,

- «Счастливого вирусства. Европа готовится к самому необычному Рождеству в своей истории» [Ъ, № 216 от 25 ноября 2020] $]^{26}$ - вирусства $\leftarrow$ вирус + (счастливого) Рождества,

- «Алкоизоляция. Ресторанная критика с Дарьей Цивиной» [Ђ, № 18 от 05 июня 2020] $]^{27}$ - алкоизолячия $\leftarrow$ алкоголь + изолячия и др.

\section{Контаминанты и аббревиатуры}

Бленды возникают не только на основе двух самостоятельных лексем, но и, как можно это заметить в газетных заголовках, путем скрещения слов или словосочетаний с аббревиатурами, ср.:

- «Алексей Навальный углубил рОЗХОждения. В связи с его отравлением МВД РФ расследует минирование аэропорта, а ООН - внесудебную расправу и нарушение свободы слова» [Ъ, № 185 от 09 октября $2020]^{28}-$ рОЗХОждения $\leftarrow$ росхождения + ОЗХХO $29-$ росхо..$+\underline{\boldsymbol{O} \mathbf{3 X \boldsymbol { O }}}$ + ...ждения,

- «Избиркомы подвергнут сертиЦИКации. Сотрудников комиссий обучат и протестируют перед выборами в Госдуму» [Ъ, № 229/П от 14 декабря 2020] $]^{30}$ - сертиЦИКация $\leftarrow$ сертификачия + ЦИК - серmu...

- «ДОНсвидания. Что будет с Договором по открытому небу после выхода из него России» [Ъ, № 6 от 16 января 2021] $]^{31}$ - ДОНсвидания

\footnotetext{
25 Речь идет о предложени ЦБ о выкупе акций дочерного банка «ФК Открытие», [online] https://www.kommersant.ru/doc/4592557 [28.11.2020].

26 [online] https://www.kommersant.ru/doc/4584915 [25.11.2020].

27 [online] https://www.kommersant.ru/doc/4366045 [03.12.2020].

28 [online] https://www.kommersant.ru/doc/4522068 [09.10.2020].

29 ОЗХО - Организация по запрещению химического оружия.

30 [online] https://www.kommersant.ru/doc/4613870 [14.12.2020].

31 [online] https://www.kommersant.ru/doc/4651763 [16.01.2021].
} 
$\leftarrow$ до свидания + ДОН (Договор по открытому небу $)-\underline{\partial \boldsymbol{o}}+\underline{\boldsymbol{Z} \boldsymbol{O}}$ + свидания,

- «В санпиническом ужасе. Владельцы гостиниц противятся новым санитарным правилам» [Ъ, № 7 от 19 января 2021] ${ }^{32}$ - санпинический

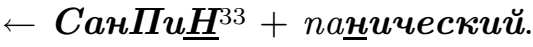

\section{Контаминанты и прецедентные тексты}

Для достижения лучшего эффекта журналистами иногда используется не один, а два приема языковой игры, заключающиеся в одновременной трансформаци прецедентных текстов и блендинге. В итоге кодировка информации в газетных заголовках проводится путем субституции одного из компонентов прецедентного текста новым блендовым образованием - гаплологическим или тмезисным контаминантом. При этом заменяемый компонент становится структурным элементом бленда, ср.:

- «Одним миром карамазаны. Лев Додин поставил постдраматического Достоевского» [Ъ, № 227 от 10 декабря 2020]34 - Братья Карамазовы + (поговорка) одним миром мазаны $\rightarrow$ карамазаны

- «Земля привитованная. Израиль вышел на первое место в мире по проценту вакцинированных» [Ъ, № 6 от 18 января 2021] $]^{35}$ - земля привитованная $\leftarrow$ прививать + земля обетованная,

- «B едимстве - сила. $\mathrm{K}$ контролю цен на продукты подключилась Федеральная налоговая служба» [Ь, № 12 от 26 января 2021]36 - едимство $\leftarrow$ (крылатое выражение) в единстве - сила + едим - $\underline{\boldsymbol{e} \partial \boldsymbol{u} н . . .}$ $+\underline{e \partial u} \boldsymbol{M}+\ldots c m в o$,

- «Жить стало векселей. ПСБ приобрел Роскосмосбанк без денег» [Ъ, № 14 от 28 января 2021] $]^{37}$ - векселей $\leftarrow$ Жить стало лучше, жить стало веселей! (слова песни 1936 г. «ЖКить стало лучше») + $\underline{\boldsymbol{\varepsilon е к c e л ь}}$ - $\underline{\text { ве... }}+\underline{\text { вексель }}+\ldots \underline{\text { селей }}$

32 [online] https://www.kommersant.ru/doc/4652998 [19.01.2021].

33 СанПиН - Санитарные (санитарно-эпидемиологические) правила и нормы (СанПиН).

34 [online] https://www.kommersant.ru/doc/4605182 [10.12.2020].

35 [online] https://www.kommersant.ru/doc/4652416 [18.01.2021].

36 [online] https://www.kommersant.ru/doc/4662002 [26.01.2021].

37 [online] https://www.kommersant.ru/doc/4663229 [28.01.2021]. 
- «Геленджить бы да радоваться. Некоторые аэропорты нарастили пассажиропоток в 2020 году» [Ъ, № 17 от 02 февряля 2021] ${ }^{38}$ - геленджить $\leftarrow$ (город) Геленджи $\kappa+$ «иㅜㅎ бы да радоватья» (заглавие книги Варвары Бурун, 2016),

- «Криптика чистого разума. Чем определяется бытие виртуальных активов» [Ђ, № 20 от 05 февраля 2021] $]^{39}$ - криптика $\leftarrow$ крити-

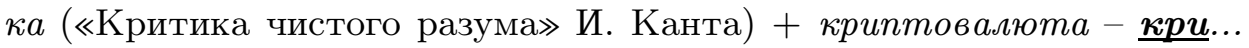
$+\underline{\boldsymbol{\kappa p} \boldsymbol{u}} \underline{\boldsymbol{m}}$ овалюта + ... $\underline{\boldsymbol{m}} \boldsymbol{u \kappa a}$.

\section{Частеречное распределение контаминантов}

Если рассматривать бленды с частеречной точки зрения, то заметим, что основу «газетных» контаминантов составляют субстантивы $(56 \%)$, sr.:

- «Франшизофрения. K чему может привести популярность модели партнерского бизнеса» [Ъ, № 27 от 14 февраля 2020] $]^{40}$ - франшизофре-

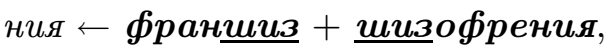

- «Вспышка коронавизуса. США могут закрыть свои генконсульства в Екатеринбурге и Владивостоке» [Ъ, № 229/П от 14 декабря 2020] ${ }^{41}$

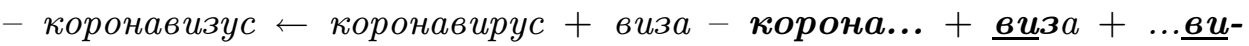
$p \boldsymbol{y c}$,

- «Карантина будущего. Дональд Трамп объяснил, чем его Америка будет отличаться от Америки Джо Байдена» [Ъ, № 201 от 02 ноября $2020]^{42}-$ карантина $\leftarrow$ карантин + вакцина и др.

Немало также адъективных блендов (18), напр.:

- «Взысключительный случай. Экс-акционерам ЮКОСа Верховный суд Нидерландов подал надежду на $\$ 50$ млрд» [Ъ, № 224 от 05 декабря 2020]43 - взысключительный $\leftarrow$ взыскание + исключительныцй,

38 О тех российских аэропортах (Геленджик, Анапа и Горно-Алтайск), в которых в период пандемии востановлены перевозки пассажиров и отмечен рост пассажиропотока из-за увеличения внутреннего туризма на фоне коронавирусных ограничений, [online] https://www.kommersant.ru/doc/4672028 [02.02.2021].

39 [online] https://www.kommersant.ru/doc/4673907 [05.02.2021].

40 [online] https://www.kommersant.ru/doc/4252834 [05.10.2020].

41 [online] https://www.kommersant.ru/doc/4614049 [14.12.2020].

42 [online] https://www.kommersant.ru/doc/4557431 [02.11.2020].

43 [online] https://www.kommersant.ru/doc/4602525 [04.12.2020]. 
- «В лицензурных выражениях. Ритейлеры просят автоматически продлить разрешения на алкоголь» [Ъ, № 213 от 20 ноября 2020] $]^{44}$ - лицензурные $\leftarrow$ лищензия + нецензурные [выражения],

- «Дальноковидная внешняя политика. Как ее увидели послы и Владимир Путин на церемонии вручения верительных грамот» [Ъ, № 216 от 25 ноября 2020] $]^{45}$ - далноковидный $\leftarrow$ дальновидный + ковид - даль-

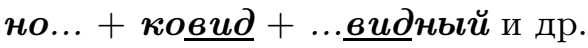

Единичны глагольные (7) и наречные слова-бленды (3), ср.:

- «Банкротство затяжбнулось. Управляющий и дольщики делят Urban Group в суде» [Ъ, № 19 от 04 февраля 2021 $]^{46}$ - затяжбнуть

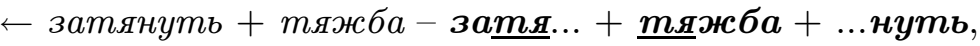

- «Азербайджан попарадовался. Победу в карабахской войне отпраздновали в Баку с участием Реджепа Тайипа Эрдогана» [Ъ, № 228 от 11 декабря 2020]47 - попарадоваться $\leftarrow$ порадоваться + парад

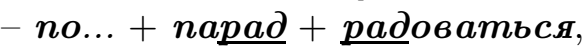

- «Пандемия аптекает. Покупатели не пожалели денег на иммуномодуляторы» [Ъ от 10 февраля 2021] $]^{48}$ - аптекает $\leftarrow$ anmeк $a+$ (прост.) y

- «На биржах всё биткойно. Американские выборы спровоцировали взлет криптовалют» [Ь, № 204 от 07 ноября 2020] ${ }^{49}$ - биткейн (биткоин) + спокойно $\rightarrow$ биткойно,

- «Конвенции следуют казахстановочно. Российский бизнес жалуется на остановку въезда порожних вагонов» [Ъ, № 24 от 11 февраля $2021]^{50}$ - казахстановочно $51 \leftarrow$ Казахстан + установочно,

- «Кредиты под включ. В полную стоимость заемных денег войдут любые сопутствующие комиссии» [Ъ, № 30 от 19 февраля 2021] $]^{52}$ - под включ $\leftarrow$ под $\underline{\boldsymbol{\kappa} л ю \boldsymbol{u}}+\boldsymbol{в к л ю ч и т ь ~ ( р а с х о д ы ) ~ и ~ п р . ~}$

\footnotetext{
44 [online] https://www.kommersant.ru/doc/4577006 [20.11.2020].

45 [online] https://www.kommersant.ru/doc/4584957 [03.12.2020].

46 [online] https://www.kommersant.ru/doc/4673303 [04.02.2021].

47 [online] https://www.kommersant.ru/doc/4606163 [11.12.2020].

48 [online] https://www.kommersant.ru/doc/4683027 [10.02.2021].

49 [online] https://www.kommersant.ru/doc/4564287 [07.11.2020].

50 [online] https://www.kommersant.ru/doc/4683588 [11.02.2021].

51 О действиях Казахстана, который в декабре вновь объявил конвенционный запрет на подачу порожних вагонов из других стран.

52 [online] https://www.kommersant.ru/doc/4694936 [19.02.2021].
} 


\section{Заключение}

Как показывают приведенные примеры применения контаминантов в строении газетного заголовка, такие формы неодериватов являются очень удобным средством привлечения внимания читателя своей уникальной структурой, игровым характером. Легость, с какой образуются блендовые новообразования, достигается с помощью включения в дериват любых материальных отрезков исходных компонентов (т.е. в полной или усеченной форме), избегая при этом ненужных чередований на морфемном (или квазиморфемном) шве, что, в свою очередь, способстувует благозвучности контаминанта. Благодаря стяжению нескольких смыслов в очень компактной форме - бленде, активизируется роль читателя, вынужденного расшифровать закодированный журналистом смысл. Между автором и читателем таким образом устанавливается диалог. Анализ газетных заголовков ежедневника «Коммерсантъ» показал, что этот диалог осуществляется журналистами путем применения в первую очередь гаплологических и тмезисных контаминантов, основу которых составляют субстантивные бленды.

\section{Литература}

Žuravlev A.F., 1982, Tehničeskie vozmožnosti russkogo âzyka v oblasti predmetnoj nominacii, [v:] Sposoby nominacii v sovremennom russkom âzyke, Moskva, s. 45-108. [Журавлев А.Ф., 1982, Технические возможности русского языка в области предметной номинации, [в:] Способы номинации в современном русском языке, Москва, с. 45-108.]

Izotov V., 2013, Tmezis kak slovotekst, «Naukovij vìsnik Hersons'kogo deržavnogo unìversitetu Serîâ "Lìngvìstika" », Vip 18, s. 243-245. [Изотов B., 2013, Tмезис как словотекст, «Науковий вісник Херсонського державного університету Серія "Лінгвістика"», Вип 18, с. 243-245.]

Izotov V.P., 2017, Tmezis: slitno, poluslitno, razdel'no, «Učenye zapiski Orlovskogo gosudarstvennogo universiteta», № 2 (75), s. 117-119. [Изотов В.П., 2017, Тмезис: слитно, полуслитно, раздельно, «Ученые записки Орловского государственного университета», № 2 (75), с. 117-119.]

Miturska-Boânovska J., 2020, Slovoobrazovatel'naâ kontaminaciâ v èpohu koronavirusa (na materiale razgovornoj reči i gazetnyh zagolovkov), [v:] Novye slova $i$ slovari novyh slov. 2020: Sbornik naučnyh statej, otv. red. N.V. Kozlovskaâ, Sankt-Peterburg, s. 176-186. [Митурска-Бояновска Й., 2020, Словообразовательная контаминация в эпоху коронавируса (на материале разговорной речи и газетных заголовков), [в:] Новые слова и словари новых слов. 2020: Сборник научных статей, отв. ред. Н.В. Козловская, Санкт-Петербург, с. 176-186.] 
Namitokova R.Û., 1986, Avtorskie neologizmy: slovoobrazovatel'nyj aspekt, Rostov-na-Donu. [Намитокова Р.Ю., 1986, Авторские неологизмь:: словообразовательный аспект, Ростов-на-Дону.]

Šumilova A.V., 2010, Okkazionalizmy netipovoj struktury v gazetnom zagolovke, «Vestnik NGU. Seriâ: Istoriâ, filologiâ», t. 9, vyp. 6: Žurnalistika, s. 131-137. [Шумилова А.В., 2010, Окказионализмы нетиповой структуры в газетном заголовке, «Вестник НГУ. Серия: История, филология», т. 9, вып. 6: Журналистика, с. 131-137.]

Ratajczyk K., 2025, Kontaminacje leksykalne. Struktura - sens - pragmatyka (na materiale rosyjskich i polskich mediów), Łódź.

\title{
Словари
}

Ahmanova O.S., 1966, Slovar' lingvističeskih terminov, Moskva. [Ахманова O.C., 1966, Словарь лингвистических терминов, Москва.]

Ènciklopedičeskij slovar'-spravočnik. Vyrazitel'nye sredstva russkogo âzyka i rečevye ošibki i nedočety, 2011, Skovorodnikov A.P. (red.), Moskva. [Энииклоneдuческий словарь-справочник. Выразительные средства русского языка и речевье ошибки и недочеты, 2011, Сковородников А.П. (ред.), Москва.]

\section{WORD BLENDS IN PRESS HEADLINES}

\author{
ABSTRACT
}

In modern Russian, word blends can be found in fiction, journalism, advertising, as well as in scientific terminology and in everyday language.

This study presents the press titles of the daily "Коммерсанть" (from 2020 and 40 issues from 2021; online version) in which lexical blends were used. Structural analysis shows that the dominant role in their construction is played by haplologic blends and blends based on tmesis ("matryoshka" words and quasi-tmesis words). An interesting procedure is the simultaneous transformation of precedent texts (substitution) and the use of word blends.

Noun derivatives are most frequently represented in the entire illustrative material. Next to them we also find adjective, verb and adverb blends.

Key words: newspaper headlines, haplologic blends, tmesis 